\title{
F-16 turbofan engine monitoring system
}

The multirole F-16 is the most advanced aircraft in the Polish Air Forces. It has been equipped with the very modern, sophisticated and advanced turbofan engine F100-PW-229. Due to the fact, that there is only one engine, its reliability, durability, efficiency and performance are the crucial factors for the safety reasons. In the article author researched maintenance system of the F100 turbofan engines, to describe Engine Monitoring System features. Engine Monitoring System (EMS) is the key element in the engine prognostic and health monitoring. The EMS provides engine fault indicators to the pilots and technicians and with the engine performance trending affects the F-16 flight safety risk and enhanced engine maintenance management concept. The main goal of this article was to provide information on the F-16 Engine Monitoring System and its impact on the aircraft airworthiness and F-16 fleet readiness resulting from the engine reliability. It is also an introduction to the F-16 Engine Health Management concept.

Key words: F100 turbofan engine, F-16, Engine Monitoring System (EMS), EDU, DEEC, Engine Health Management (EHM)

\section{Introduction}

The F-16 engine indicating and monitoring system allows the operator, either a pilot or technician to follow and monitor engine operation and performance.

F-16 Engine Monitoring System (EMS) (Fig. 1) provides an electronic flow of engine life usage data to the engine tracking systems. The EMS also collects information during engine operation to support maintenance personnel during engine troubleshooting. These features allow for increased aircraft availability, reduced maintenance man-hours per Engine Flight Hour (EFH), and more accurate tracking [8].

The Engine Monitoring System (EMS) forms an integral part of the overall engine maintenance management plan. The EMS acquires relevant engine data during flight. It analyzes the data and provides a concise output at the
Aircraft Maintenance Unit (AMU) being flightline level to define required maintenance actions and to allow transfer of data to ground support equipment for appropriate levels of analysis and usage [1].

The main purpose of the EMS is to:

a) Determine which control system is installed and select the appropriate set of diagnostic algorithms for accurate Line Replaceable Unit (LRU) isolation.

b) Detect in-flight failures, set faults and isolate failures to the appropriate LRUs where possible.

c) Record pre- and post-event data when specific operational limits are exceeded.

d) Establish EMS fault and engine NO-GO indications that lead to determination of appropriate maintenance actions required at the flightline.
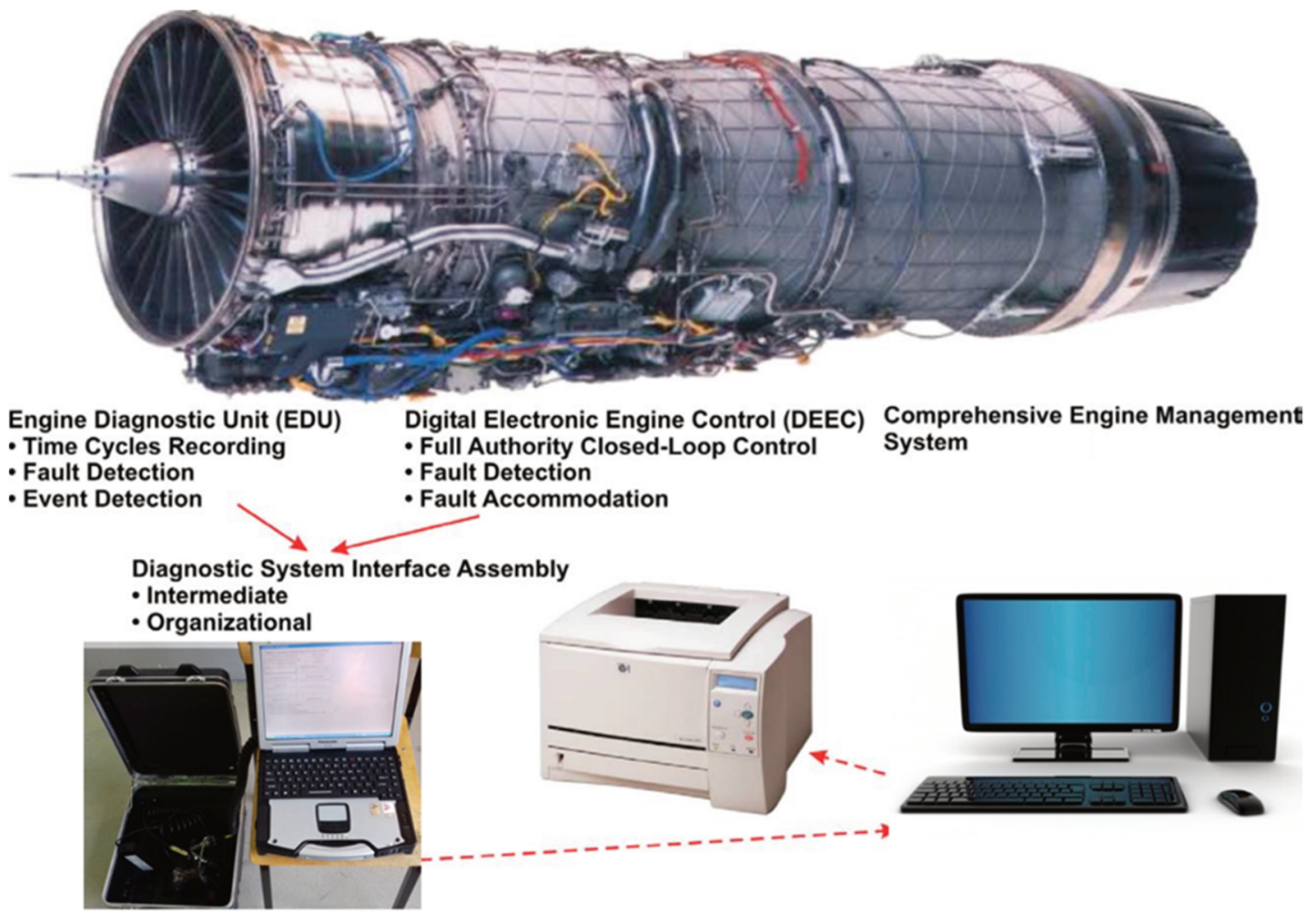

Comprehensive Engine Management

- Fault Detection

- Fault Accommodation

Diagnostic System Interface Assembly - Intermediate

- Organizational

Fig. 1. Engine Monitoring System 


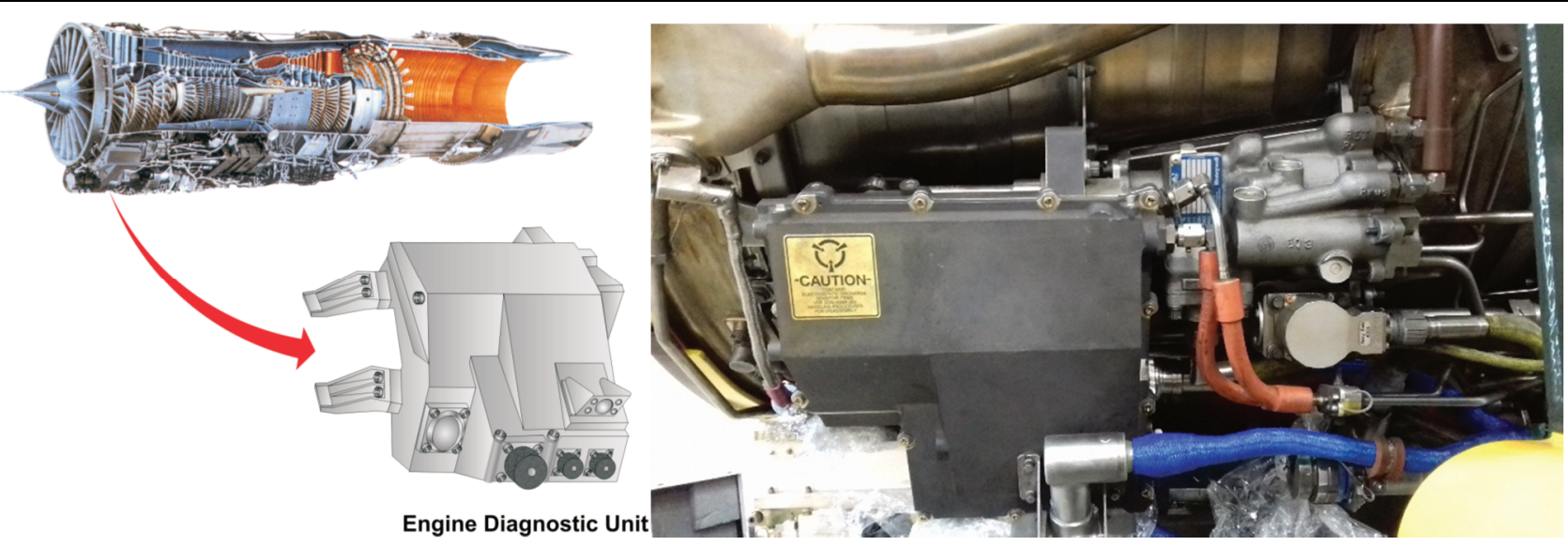

Fig. 2 Engine Diagnostic Unit (EDU)

e) Acquire parts life tracking and trending data for processing by ground support equipment and parts tracking systems.

The EMS is composed of these basic units:

a) A Digital Electronic Engine Control (DEEC) - engine mounted (Fig. 3).

b) An Engine Diagnostic Unit (EDU) - engine mounted (Fig. 2).

c) Comprehensive Engine Diagnostic Set (CEDS) (Fig. 10), Common Engine Transfer System (CETS), or Data Transfer Set (DTS) - ground equipment.

d) Comprehensive Engine Trending And Diagnostic System (CETADS) and Intelligent Trending and Diagnostic System (ITADS) or equivalent Ground Station Computer (GSC) - ground equipment.

The heart of the F100 EMS is the Engine Diagnostic Unit (EDU) (Fig. 2). This computer acquires control system and engine data from the DEEC, engine sensors, and aircraft inputs. In addition to the DEEC, the EDU (with the aircraft integrated diagnostic system), provides fault detection using acquired data. These data are also used to record maintenance information on faults and engine operation. This computer contains logic software that analyzes engine sensor data to determine engine operational integrity. The EDU records an engine anomaly as a fault message and identifies the event during flight. The EDU records fault codes, selected engine operating parameters, and time/cycle data. This fault and event data is transmitted to the Modular Mission Computer (MMC) and can be accessed in the F-16 cockpit on the Multifunctional Display (MFD) in the form of a Maintenance Fault List (MFL). Faults that require pilot action or reduce mission capabilities are displayed on the Pilot Fault List (PFL) [11].

The EDU provides the engine-to-airframe communications interface. The EDU acts as the main interconnect box for engine/aircraft signals. An event or control system fault that requires maintenance action or indicates potential engine damage will cause the EDU to trip a no-go maintenance alert flag on the Avionics Status Panel (ASP). After each flight the maintenance crew checks the ASP. If the engine no-go flag is tripped (Fig. 4), the maintenance crew uses the CEDS to retrieve the maintenance information within the EDU. If the engine no-go flag is not tripped, the engine is released for flight or the CEDS can be used to retrieve time/cycle data (at the end of the flying day). Faults requiring maintenance action before the next flight will set an EMS indicator.

Aircraft specific Fault Isolation (FI) manuals provide troubleshooting trees for fault message) and direct appropriate maintenance actions.

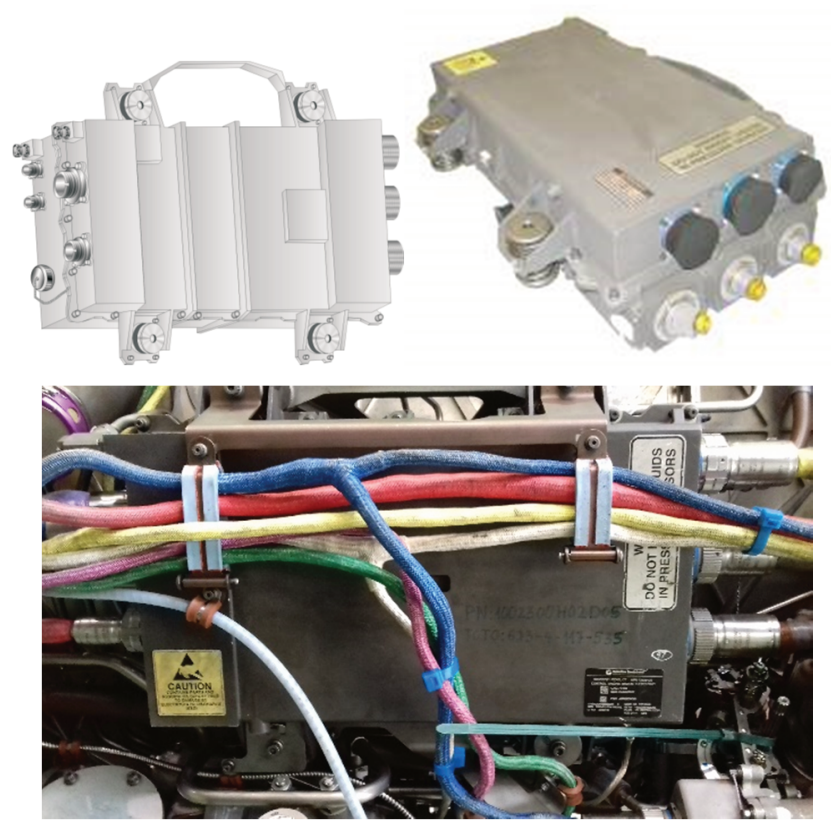

Fig. 3 Digital Electronic Engine Control (DEEC)
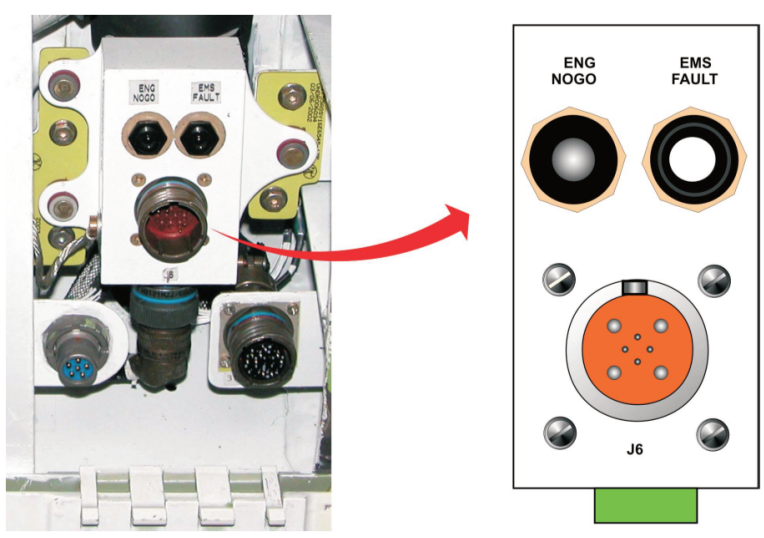

Fig. 4. F-16 System Fault Flags 


\section{EMS data flow}

The EMS becomes operative at engine start and records performance data at takeoff. There are two types of Takeoff performance data: MIL-POWER (PLA between 83 and 90 degrees) and MAX-POWER (PLA at or above 90 degrees).

Sensor inputs from the engine are processed by the DEEC. The DEEC conditions and digitizes these signals for transmission to the engine mounted EDU. The EDU receives these signals, as well as signal inputs from the aircraft and performs diagnostic logic and data storage. Data downloading from the EDU is accomplished by connecting the CEDS, CETS or DTS to the engine. There are six types of DEEC and EDU fault or code categories: Event (EVT) codes-1000 series, DEEC faults-2000 series, EDU faults3000 series, System faults-4000 series, Advisory faults5000 series and Performance advisories-6000 series. ITADS faults are the 8000 series. This data is then downloaded into the ground station software, which is currently CETADS and ITADS.

EMS data flow is presented at Fig. 5.

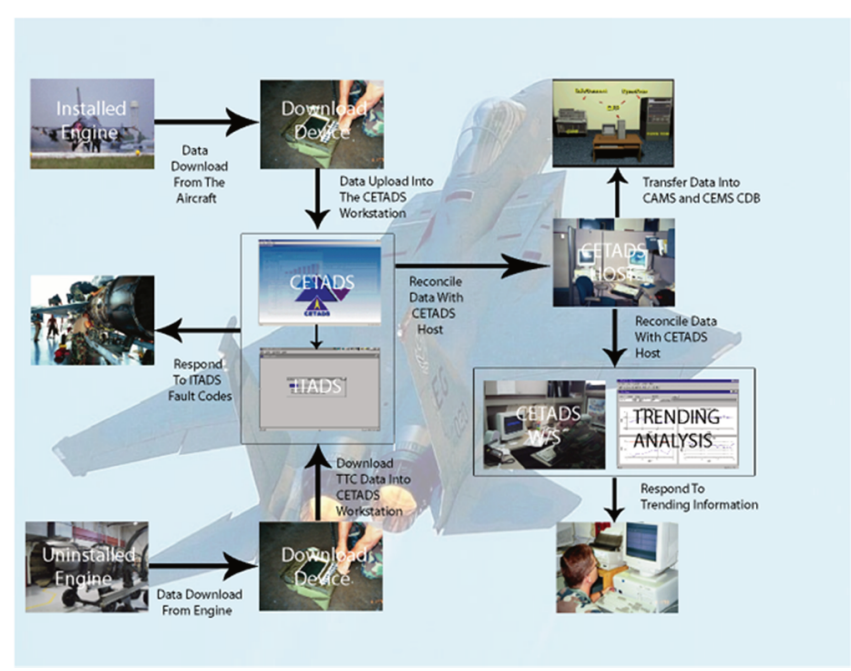

Fig. 5. EMS Data Flow

The Engine Diagnostic Unit (EDU) (Fig. 2) is an engine mounted, fuel cooled, self-contained diagnostic computer used in Monitoring System that operates with conjunction with the DEEC gr. $\mathrm{V}$ to acquire and record diagnostic data when the engine is operating. EDU stores data that could be collected later on with Engine Monitoring Support Equipment (EMSE) for further evaluation and analysis. The EDU receives and stores engine and aircraft sensor data, and control system data from the DEEC. These signals and data are monitored by the EDU to detect control system faults and engine malfunctions. When the EDU detects a system fault or anomaly, it records a 3-digit fault code, along with the time of event. This information is stored in the EDU and is retrievable at the flightline level for troubleshooting. The EDU receives and stores data in six basic engine usage data groups: (Fig. 6) [1].

1. Time/Cycle Data. The EDU monitors the engine for overlimit conditions. In addition, it accumulates low cycles fatigue counts and engine flight hours.

2. Event Data. The EDU monitors the engine for overlimit conditions and anomalies. The data is stored in three parts: a three digit code number which identifies the event, the elapsed time when the event occurred and critical parameters to establishing minimum maintenance requirements.

3. Fault Data. The EDU records engine control system, DEEC and EDU faults. The fault data is used to determine maintenance requirements. Faults are stored in two parts: three digit code number which uniquely identifies the source of the fault.

4. Transient Data is recorded in the EDU when an auto transfer to SEC has occurred, a random or recurrent event has taken place or when requested by the operator by positioning the AB RESET switch to ENG DATA position.

5. Performance Data. During any of the two engine operating conditions, the EDU automatically records nine parameters. The operating conditions are: on the ground at intermediate power or takeoff at intermediate or maximum power.

6. Documentary Data. It is used to for parts life tracking and configuration management.

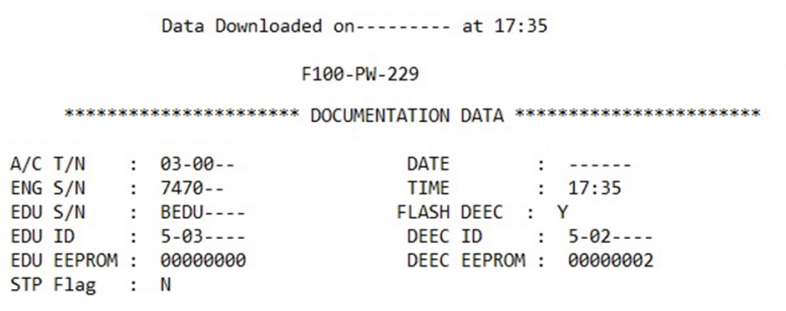

\begin{tabular}{|c|c|c|c|c|c|}
\hline MAN & : & 288 CYCLES & HS2 & : & 0.10 HOURS \\
\hline LCF & : & 3291 CYCLES & HS3 & : & 9.77 HOURS \\
\hline CY4 & : & 6061 CYCLES & HS4 & : & 1.03 HOURS \\
\hline EOT & : & 649.30 HOURS & $A B T$ & : & 8.24 HOURS \\
\hline IFT & : & 378.60 HOURS & $A B C$ & : & 1493 CYCLES \\
\hline HS1 & : & 2.67 HOURS & CM3 & : & 0 CYCLES \\
\hline NC1 & : & 1188 CYCLES & EOTM & : & 77.50 HOURS \\
\hline NC2 & : & 1597 CYCLES & ASLTM & : & 0.00 HOURS \\
\hline NC3 & : & 7245 CYCLES & NDELACT & : & 0.00 HOURS \\
\hline $\mathrm{AJL}$ & : & 27881 SQFT & PDELACT & $:$ & 0.00 HOURS \\
\hline AJM & $:$ & 20810 SQFT & NDELBTM & : & 0.00 HOURS \\
\hline AJH & : & 1147 SQFT & PDELBTM & : & 0.00 HOURS \\
\hline PTT & : & 0.00 HOURS & & & \\
\hline
\end{tabular}

Fig. 6. EDU Engine Data

The F-16C/D Block 52 is powered by the Pratt \& Whitney F100-PW-229 low-bypass, high compression ratio, fully ducted, twin-spool turbofan engine which incorporates a FADEC Digital Electronic Engine Control (DEEC).

The Digital Electronic Engine Control (DEEC) is a fuel cooled, engine mounted, full authority, electronic control, digital computer (Fig. 3). It is mounted to the front fan duct, on the left side, at approximately the 8 o'clock position. The DEEC provides precise management of thrust and airflow in response to Power Lever Angle (PLA) changes while in the Primary (PRI) mode of operation. It monitors engine temperature, speed, and pressure limits, while maintaining stall margin during steady state and transient conditions. The DEEC continually examines and accommodates control system faults. These faults are recorded as a threedigit code and stored in the DEEC, and then transferred to the EDU. If the DEEC cannot control the engine due to an 
engine fault, or a problem with the system itself, engine control is transferred to the Secondary (SEC) mode portion of the Main Fuel Control (MFC), thus placing the engine in SEC mode of operation.

The DEEC responds to approximately 50 input parameters and provides approximately 20 outputs to the hydromechanical components (Fig. 7). The DEEC provides the engine system with maximum level of save operation along with fault detection and accommodation. Polish Air Force are using two series of DEEC: group V and Group VI. The Group VI DEEC will incorporate all functionality of the EDU [3].

Input signals for DEEC gr V:
a) Fan inlet static pressure (Ps2)
b) Burner pressure $(\mathrm{Pb})$
c) Fan turbine discharge pressure (Pt6m)
d) Fan inlet temperature ( $\mathrm{Tt} 2)$
e) Fan turbine inlet temperature (FTIT)
f) Front compressor speed (N1)
g) Rear compressor speed (N2)
h) Geometry position signals from Resolvers
i) Augmentor light-off detector (LOD)
j) Ps2 resistance temperature detector (RTD)
k) Metering/sequencing Valve position
1) Several airframe signals

m) Automatic warning system tures:

DEEC VI Series: DEEC group VI has additional fea-

a) Temperature sensor TT3

b) Instead of EDU there is Prognostic Health Monitor (PHM) built in DEEC (more memory available, higher resolution of data scan)
c) Predictive Prognostics
d) Useful Life Remaining Predictions
e) Component Life Tracking
f) Performance Degradation Trending
g) Selective Fault Reporting - Only tells pilot what NEEDS to be known immediately - Informs Maintenance of the rest of the engine information

h) Supports Maintenance Decision Making \& Resource Management
i) Fault Accommodation
j) Information Management

The DEEC monitors engine operation for possible anomalies. If an anomaly is detected, the DEEC will record the anomaly and inform the Engine Diagnostic Unit (EDU). The DEEC also takes corrective action depending on the severity of the anomaly.

There are 5 Engine Control Loops (Fig. 8):

a) Compressor Inlet Variable Vanes (CIVV)

b) Rear Compressor Variable Vanes (RCVV)

c) Main Fuel Control (MFC)

d) Augmentor Fuel Control (AFC)

e) Exhaust Nozzle Area (AJ)

Compressor Inlet Variable Vanes - its purpose is to improve fan efficiency and stall margin by controlling the air entering the fan.

a) Primary Mode Control

- Scheduled as a function of fan speed and TT2

b) Secondary Mode Control

- Move to fully cambered position

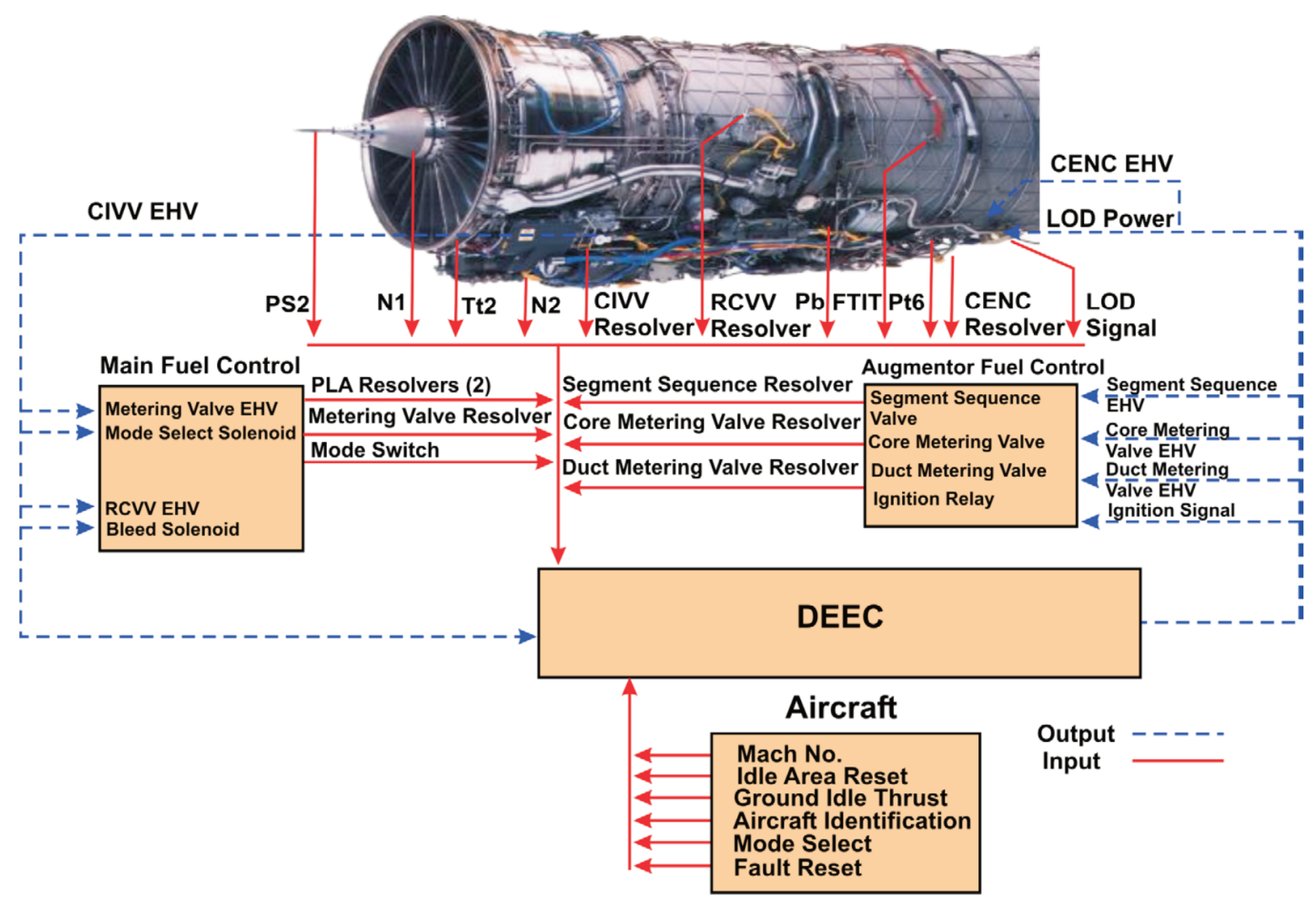

Fig. 7. F-16 Engine sensors and control - DEEC Inputs and Outputs [3] 


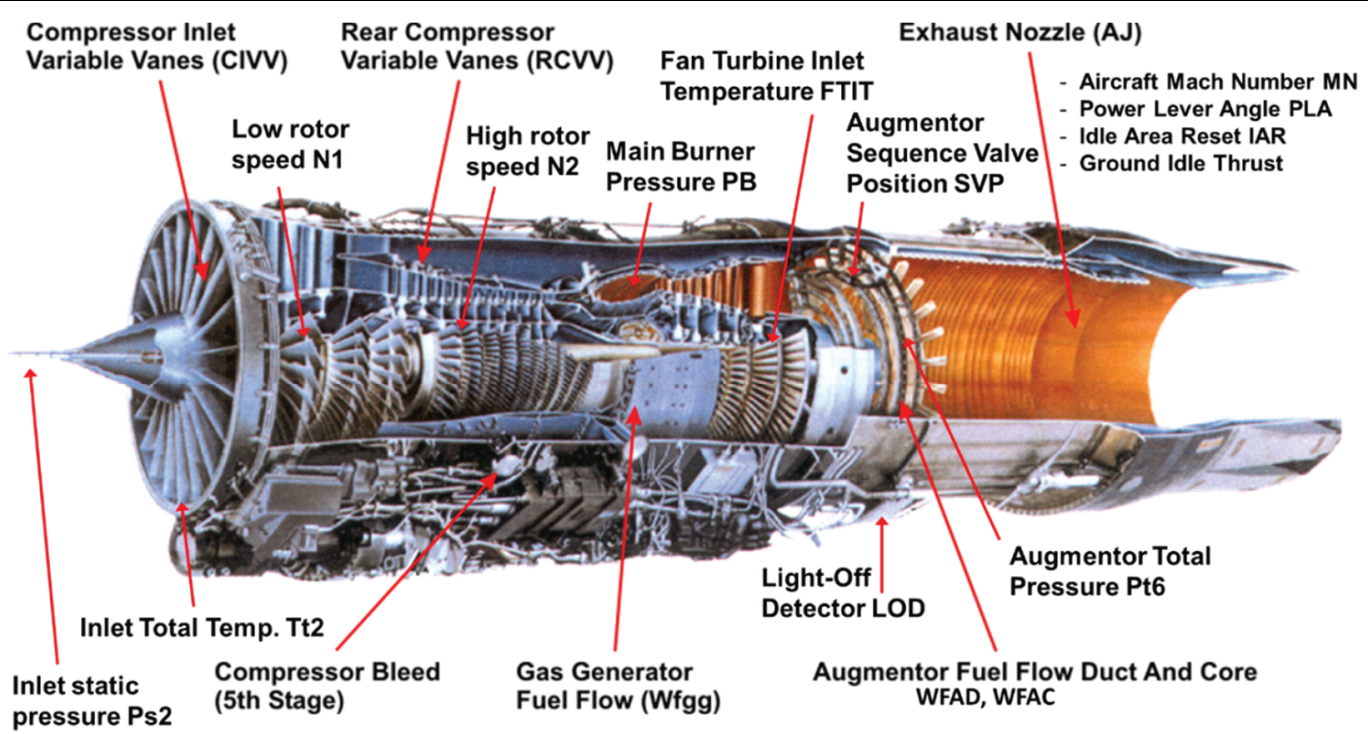

Fig. 8. Digital Electronic Engine Control Inputs and Outputs [7]

Rear Compressor Variable Vanes - its purpose is to maintain satisfactory compressor performance and stall margin over a range of operating conditions by varying the angle of the core inlet guide vanes and the following 3 stages of core stator vanes

a) Primary Mode Control

- Scheduled as a function of core speed, fan speed and TT2

b) Secondary Mode Control

- Scheduled as a function of core speed and TT2

Main Fuel Control - its purpose is to meter fuel to the core engine to increase thrust levels as a function of pilot demand.

a) Primary Mode Control

- Scheduled to maintain fan speed and EPR request, but can be overridden to ensure adequate speed, pressure temperature limits are maintained. In order to support normal engine operation in this mode MFC controls the following actions:

- increases and decreases fuel flow as scheduled by the DEEC;

- provides actuation pressure to CIVV control and cylinder;

- actuates RCVV system as scheduled by the DEEC;

- sends primary/secondary mode signal to DEEC and airframe;

- provides washed/filtered fuel regulated servo pressure to engine servos;

- actuates compressor bleed system as scheduled by the DEEC.

b) Secondary Mode Control

- Scheduled to maintain safe temperature, speed and stall margins in the absence of active speed and temperature limits. In this mode MFC reacts on:

- hydro-mechanical control of fuel flow using PLA, TT2 and PS2 as inputs.

- schedules RCVV system with TT2 and N2 as inputs.

- provides washed/filtered fuel regulated servo pressure to engine servos.

- actuates compressor bleed system during start.
During routine/daily maintenance data stored in the EDU and DEEC can be manually downloaded after every flight and viewed. Then fault data if used for troubleshooting and also to check the EDU and DEEC for any malfunctions. Data is also sent to the engine tracking section where the documentation data is checked for proper numbers.

There are five basic types of faults identified. Each fault is identified with a four digit-code.

1. DEEC V fault series:

a) 1000 series Event Fault : engine anomalies such as hung start and FTIT overtemperatures.

b) 2000 series: DEEC Fault

c) 3000 series: EDU Fault

d) 4000 series: System Faults (any control system anomalies)

e) 5000 series: Advisories

2. DEEC VI Series:

a) 1000 series: Engine anomailes

b) 2000 series: DEEC Fault

c) 4000 series: System Faults

d) 5000 series: Advisories

\section{Engine Tracking System}

Engine data is permanently stored by the Engine Tracking System (ETS). Complete engine history can be recalled in various reports from this system. The ETS consists of either: Comprehensive Engine Management System Increment IV (CEMS IV) used by the United States Air Force (USAF) to track engines, or Advanced Compact Engine Tracking System (ACETS) used by the air forces of other countries to track their engines [9].

The ETS tracks engines/components requiring time change and/or Time Compliance Technical Order (TCTO) action.

Transfer/download of data from the EDU is accomplished using Engine Monitoring Support Equipment (EM$\mathrm{SE}$ ), which consists of the following:

a) Comprehensive Engine Diagnostic System (CEDS) provides complete capability to interface with the EDU/DEEC and to monitor/record engine operation in a lightweight unit. 
b) The downloaded data is used to aid maintenance personnel and is transferred to the engine tracking section

The Comprehensive Engine Diagnostic Unit (CEDS) is a ground-based data collection and diagnostic system (Fig. 9) that supports F100 engines using the Engine Monitoring System (EMS). The CEDS acquires, processes, and displays engine data to maintenance crews and can transfer the data to Air Force tracking systems, such as:

a) Comprehensive Engine Management System Increment IV (CEMS IV)

b) Advanced Compact Engine Tracking System (ACETS).

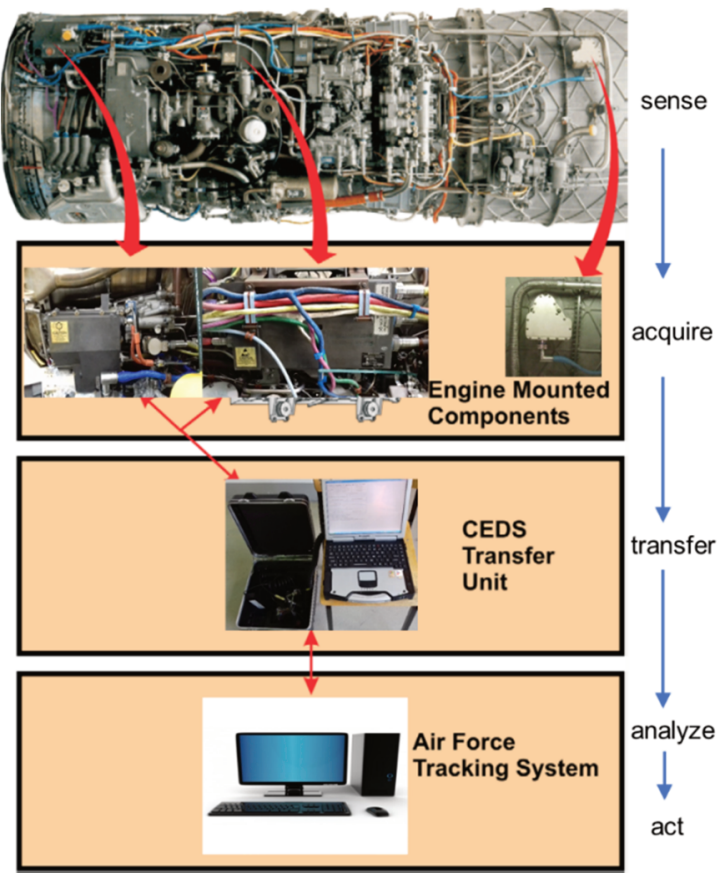

Fig. 9. Typical Engine Monitoring System

The CEDS is used to communicate with the Engine Diagnostic Unit (EDU), Digital Electronic Engine Control (DEEC), and Data Collection Unit (DCU).

\section{Engine Downloading}

Downloading is usually performed using a single CEDS transfer unit (Fig. 10) to download all aircraft in a section.

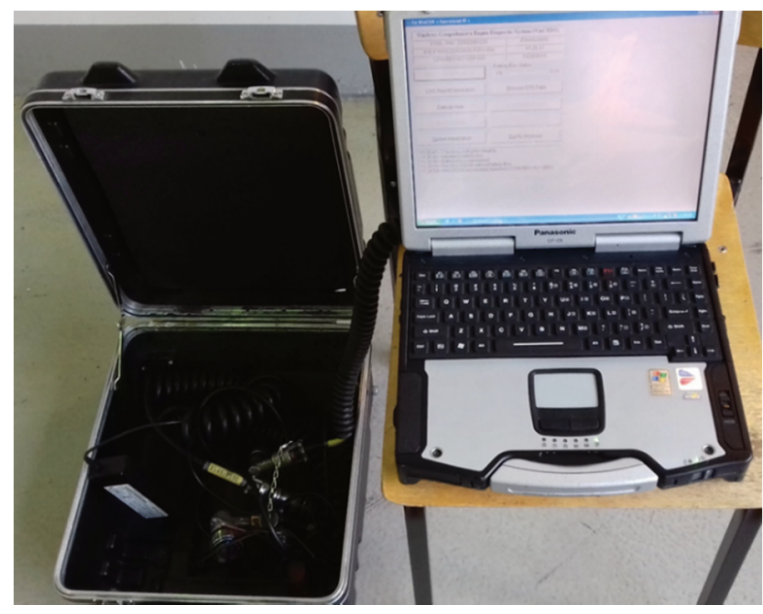

Fig. 10. Comprehensive Engine Diagnostic Set CEDS
This configuration is typically used at the end of the flying day, if the pilot reported an engine anomaly, or in the event of an EMS-reported engine malfunction (aircraft NOGO flag tripped).

DEEC download capability supports special investigations and is not required during normal maintenance.

Only fault code data will be downloaded (without a time stamp). This data is for read-only purposes and will not be stored in the CEDS.

\section{Engine Monitor}

CEDS allows the operator to perform real-time monitoring of an aircraft-installed engine (O-Level) [3].

This is typically performed during engine troubleshooting or operational checks, as required by the applicable Technical Order (T.O.).

The Intermediate Maintenance (IM or I-Level) is used at the test cell, after engine maintenance, or when troubleshooting, as required by the applicable T.O. The CEDS transfer unit is permanently mounted in the control room of the Hush House in conjunction with the interconnecting box (Fig. 11).

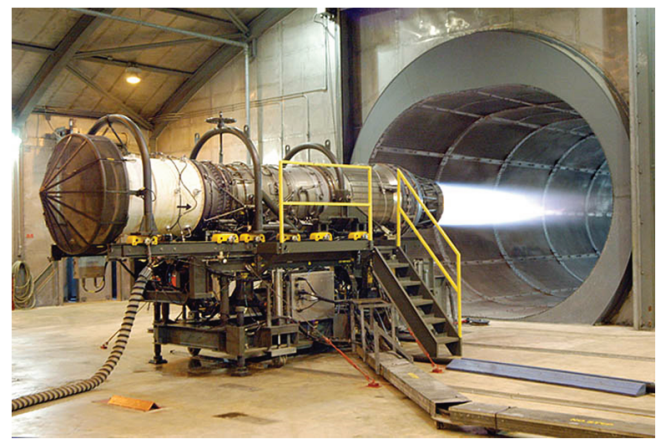

Fig. 11. Engine Monitoring System at I-Level

The EDU downloads are normally done at the end of the day for flight-line operations, at the end of the acceptance test for test cell operations, or when faults are detected by the EMS.

The EDU download summary report (Fig. 12) provides a brief summary of downloaded data. An option is provided for the operator to examine the download data in detail. When downloading data from the EDU, CEDS will store identical data into two locations. One location is a file to transfer data to Air Force tracking systems. The other location stores the data in the CEDS database (internal memory). Up to 500 complete downloads may be stored in CEDS memory at a time.

Once CEDS memory is full, subsequent downloads are accommodated by deletion of the oldest data in CEDS memory. The transfer file grows continuously until the data is transferred to Air Force tracking systems or CEDS runs out of memory.

If CEDS detects an error during its operations, messages will be displayed to inform the operator of a malfunction.

CEDS (Fig. 10) allows the operator to download/view DEEC fault codes, clear DEEC fault codes, update DEEC logic, perform an LOD test, and view the memory locations within the DEEC that may be required to support special investigations, as requested by $\mathrm{P} \& \mathrm{~W}$. 


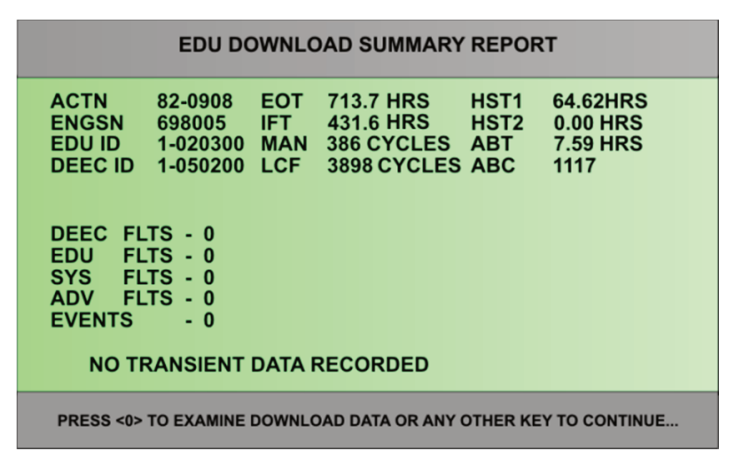

Fig. 12. EDU Download Summary Report

\begin{tabular}{|c|c|}
\hline \multicolumn{2}{|c|}{ Windows Comprehensive Engine Diagnostic System (WinCEDS) } \\
\hline $\mathrm{F} 100-\mathrm{PW}-220 / 220 \mathrm{E} / 229$ & PWA500665 \\
\hline 81E-F100/CDD/G6/US-F001-00 & $09: 30: 44$ \\
\hline CPIN REV 007 VER 000 & $11 / 28 / 2018$ \\
\hline Battery Box Status & $100 \% \square 29.0 \mathrm{~V}$ \\
\hline EMS Report Generation & Process ETS Data \\
\hline Data Archive & Reprogram Group 6 \\
\hline \multicolumn{2}{|l|}{ Engine Monitor } \\
\hline System Initialization & Exit To Windows \\
\hline $\begin{array}{l}\text { 09:30:25> Checking config file integri } \\
\text { 09:30:25> Logic C.IProgram Filesilus } \\
\text { 09:30:26> Initializing battery box.... } \\
\text { 09:30:34> Battery box code loaded } \\
\text { 09:30:34> WinCEDS6 successfully la }\end{array}$ & $\begin{array}{l}\text { SAFIF100WInCEDSGWCEDS } \\
\text { aunched. (CPIN REV } 007 \text { VER } 6\end{array}$ \\
\hline
\end{tabular}

Fig. 13. CEDS menu

\section{EMS Report Generator}

The EMS Report Generator option (Fig. 13-14) allows the generation and display of EMS data in several different screen formats.

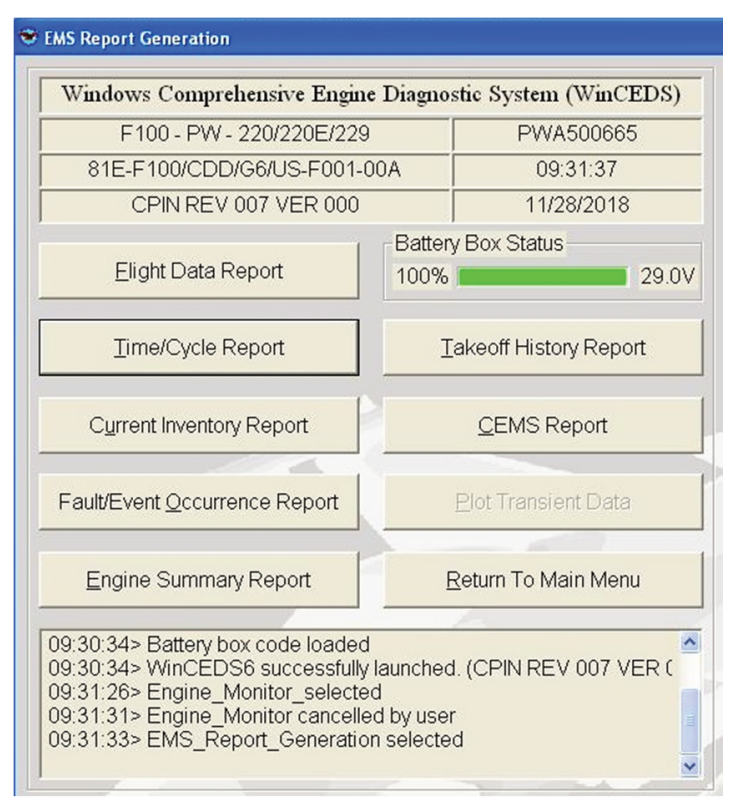

Fig. 14. EMS Report Generator submenu
The secondary menu options are described on the following pages.

1. Flight Data Report - This option allows the operator to view all or selected parts of information recorded from a selected engine for a single download.

The data may be contained on several different screens (Fig. 15-20). It shows all downloads stored in CEDS for the engine selected like:

1. Documentation data and time/cycle data:

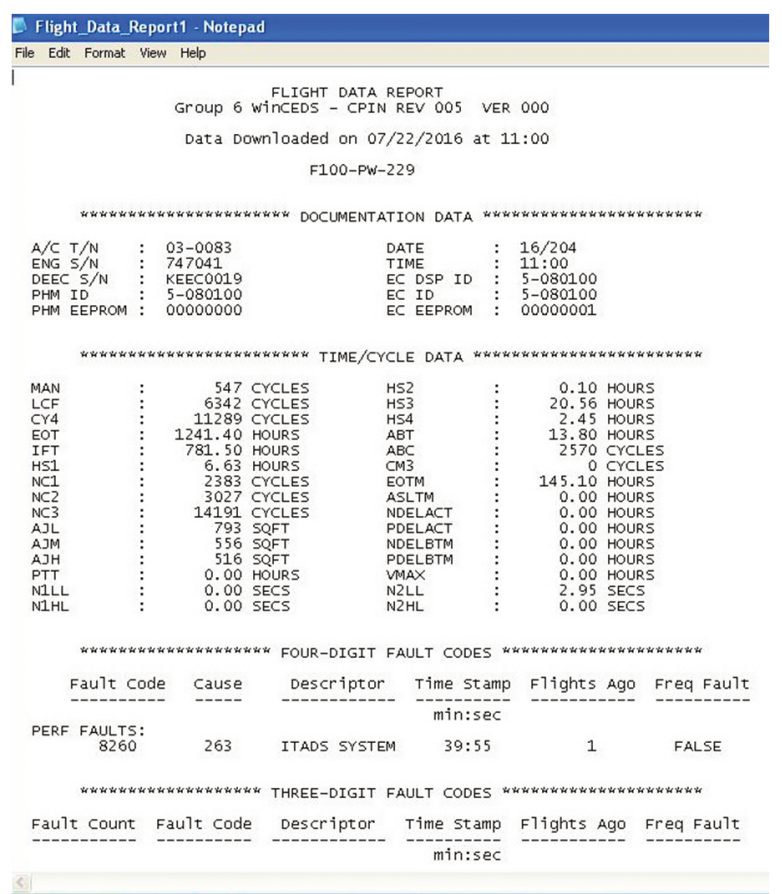

Fig. 15. Documentation data and time/cycle data

\section{Engine Fault Data:}

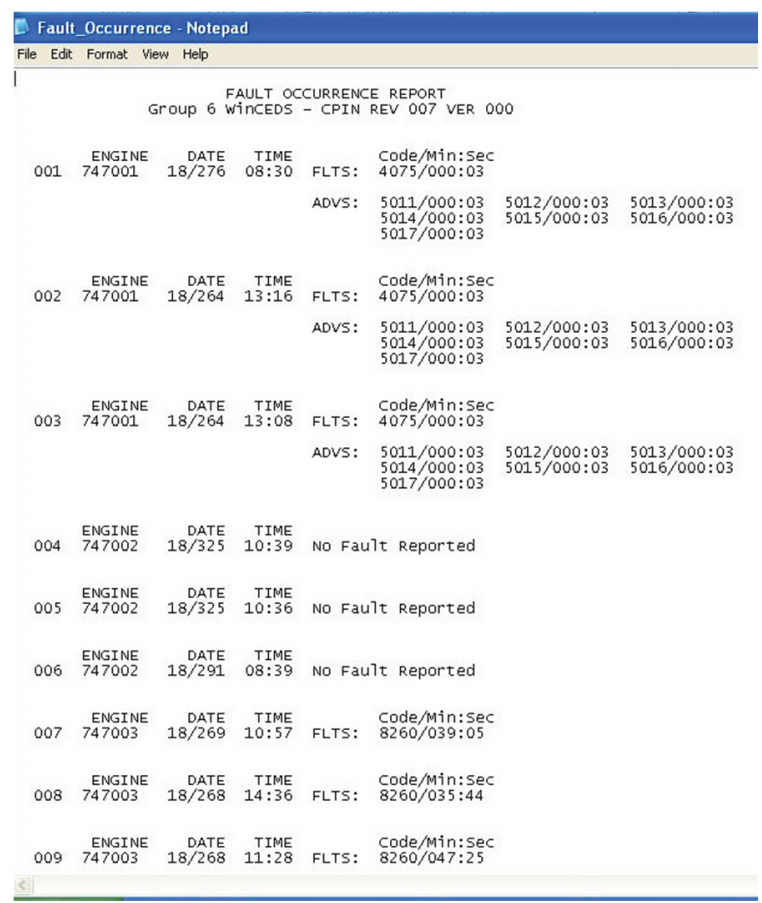

Fig. 16. Engine Fault Data 
3. Engine Performance data:

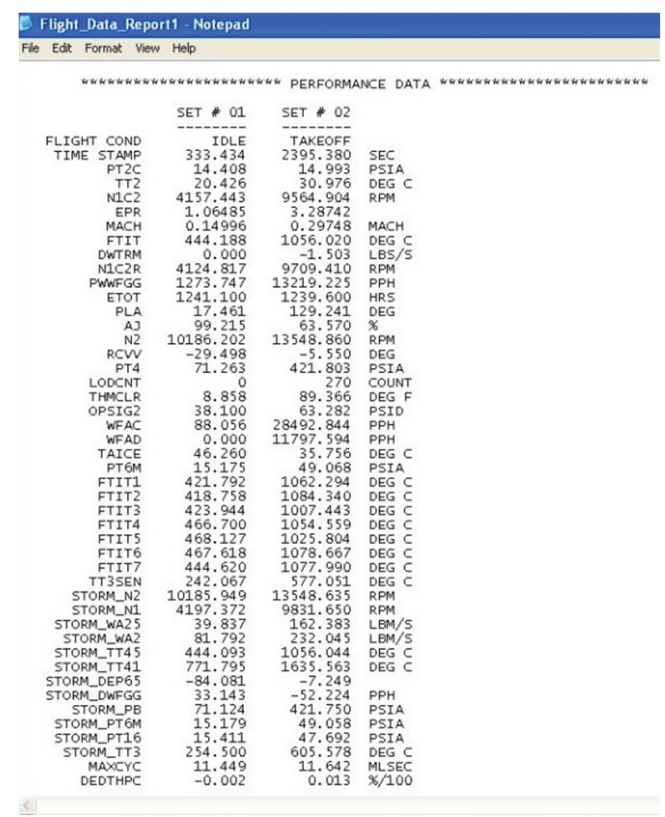

Fig. 17. Engine Performance Data

4. Event (maintenance) Data;

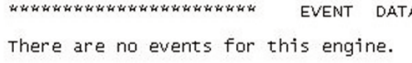

Fig. 18. Event (maintenance) Data

\section{Engine Advisory Data:}

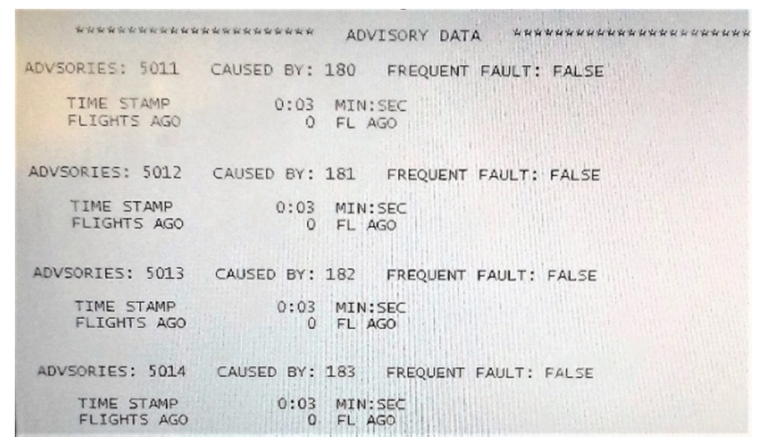

Fig. 19. Engine Advisory Data

\section{Transient data.}

There are no transient data for this engine.

Fig. 20. Engine Transient Data

\section{Engine Monitor}

The engine monitor option allows the operator to view/record real-time EDU (Fig. 21) or DEEC (Fig. 22) with the engine running or view DEEC parameters when the engine is static. The operator is presented with a display of selected parameters and may select up to four additional parameters.

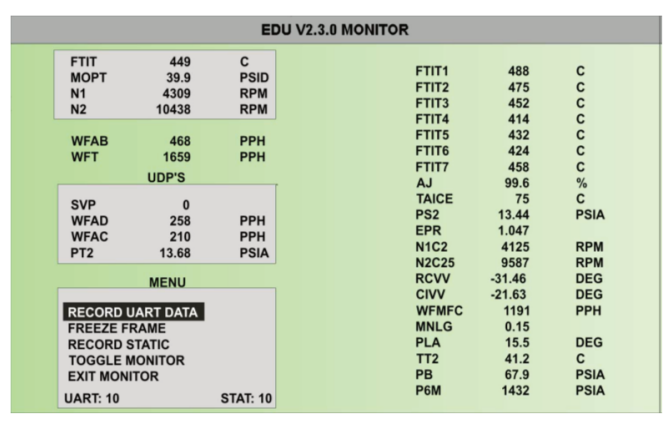

Fig. 21. EDU Real Time Monitor

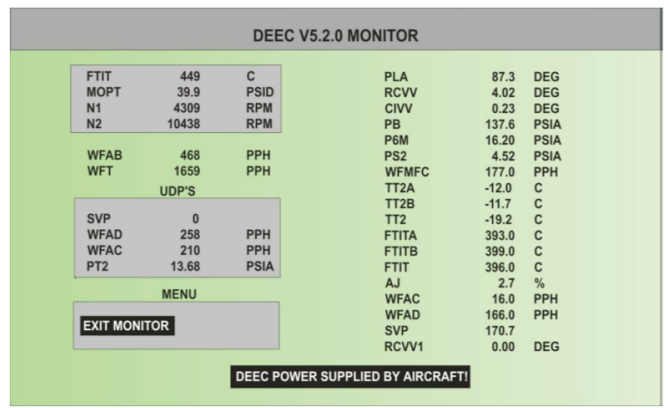

Fig. 22. DEEC Real-Time Monitor

\section{Troubleshooting scenario for flightline operations}

When the aircraft returns, the ground crew performs the required postflight inspections including a check of aircraft system fault indicators. The ground crew takes the following actions based on the fault indicator flags.

When neither flag (Fig. 4) is tripped (NO-GO or EMS), the aircraft is released. When the NO-GO or EMS BIT flags are tripped, the technician uses Engine Maintenance Support Equipment (EMSE) to download the EDU and extract fault data.

If a fault has been recorded by the EMS, the technician refers to the Technical Order (T.O.) work package, which contains information required to troubleshoot the fault and return the engine to service.

There may be instances when the pilot or engine operator may complain about improper engine operation, but the EMS will not indicate a need for troubleshooting (no fault or event codes).

\section{Aircraft Indications}

Troubleshooting usually begins with an engine malfunction reported by the pilot. Most engine anomalies will be reported by the pilot and recorded by the EMS. However, some engine faults will be recorded only by the EMS (without the pilot noticing any fault exists). The pilot may report some engine anomalies only (no EMS data).

Cockpit indicators can be verified to ensure that the fault exists with the engine and not the airframe. It is done by using the Comprehensive Engine Diagnostic System (CEDS) to check the engine EMS faults that are recorded. Indicators in the cockpit may be erroneous due to an airframe malfunction.

The pilot monitors engine parameters through gauges mounted in the cockpit (Fig. 23). 


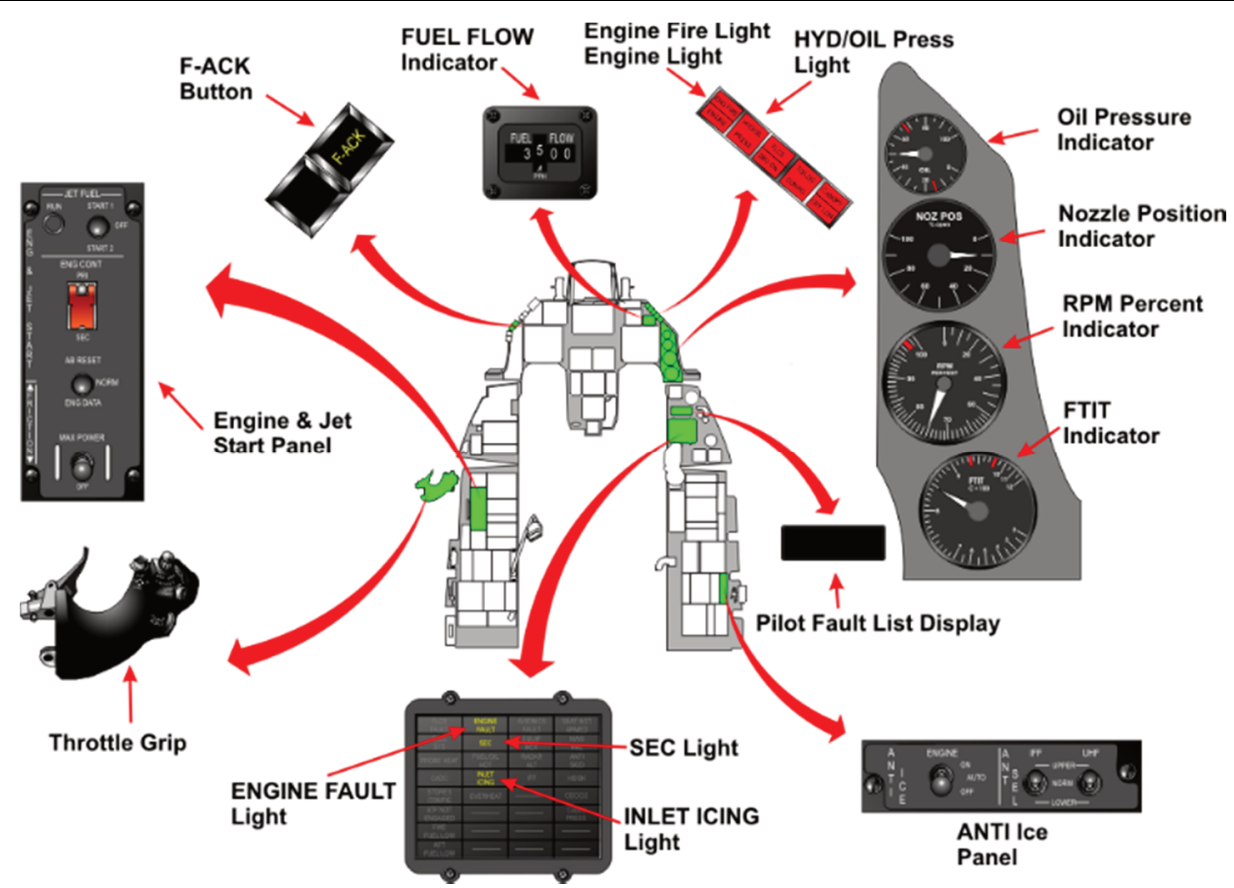

Fig. 23. Engine Controls and Indicators [1]

Table 1. Engine indicators

\begin{tabular}{|l|c|}
\hline \multicolumn{1}{|c|}{ Indicator } & Description \\
\hline HUD (Head-Up Display) & Warnings, Fuel, Pilot Fault List (PFL) \\
\hline Master Caution & Engine Bay Temperature $>765^{\circ} \mathrm{F}$ \\
\hline Engine Fire & Engine Oil Pressure $<10$ PSI \\
\hline HYD/OIL & Engine overtemperature, flameout or stagnation \\
\hline ENGINE & Pilot Fault List \\
\hline PFLs (located on the data entry display) & Loss of the Mach signal to the DEEC \\
\hline A/B Failure & Anti-ice problems \\
\hline Mach No. Failure & Anti-ice problems \\
\hline DEEC/EDU Communication Failure & Engine Low Thrust \\
\hline Anti-ice overtemperature & Loss of the multiplex (MUX) communication to the EDU/DEEC \\
\hline Anti-ice valve Failed Closed & PFL Fault present \\
\hline Engine Low Thrust (indicates both FTITA and FTITB signals failed) & Engine bay overheat \\
\hline A/C Engine MUX-Bus Failure & Caution Panel, Engine in Secondary Mode (SEC) \\
\hline Engine Fault & Fondition Present \\
\hline Overheat & Upgraded Central Air Data Computer Failure \\
\hline Inlet Icing & \\
\hline Fuel/Oil Hot & \\
\hline UCADC & \\
\hline
\end{tabular}

The engine parameters that are monitored in the cockpit are:

1. Core rotor speed: N2 (\% RPM)

2. Fan turbine inlet temperature: FTIT $\left({ }^{\circ} \mathrm{C}\right)$

3. Fuel flow: (PPH)

4. Exhaust nozzle position: ENP (\%)

5. Main oil pressure: MOP (PSI).

Caution lights alert the pilot to warnings or malfunctions and indicate the engine system affected. The pilot takes appropriate action required by the indication.

F-16 engine indicators are shown in Table 1.

\section{Engine fault troubleshooting procedure}

Engine troubleshooting procedures are the part of Technical Manual Fault Isolation Power Plant MODEL F100-
PW-229 [12]. This manual provides fault identification, description and isolation procedures for power plant system.

Fault Identification and Description.

The fault diagnostic logic information appears in the body of the page in block flow form (Fig. 24). This form identifies the fault as well as relevant conditions leading to a specific eight-character numeric-alphanumeric code. It provides the conditions existing at the time the fault occurred and/or, when applicable, a crossreference listing from self-test failed test number to a fault code.

As an example, a complete fault code as would appear on a fault identification page or in a job guide test result (except for location code) is as follows: 70-00-AD-00. The fault code elements are broken down as follows: 


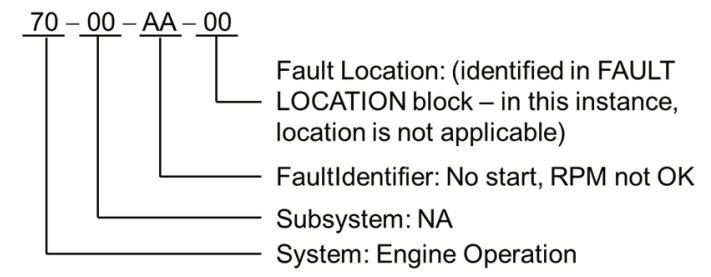

The two-letter fault identifier used to identify faults is assigned so that the first letter identifies the basic fault. The second letter identifies a subfault found within the basic fault.

\section{Fault Isolation Procedures}

The user will find the fault isolation procedure for the required fault code on the appropriate fault isolation procedure flow chart. Each fault code is followed by a series of action instructions contained in rectangular blocks with the monitored results of the actions outside the blocks (Fig. 24). These actions terminate with fault correction instructions or reference to a schematic diagram or another system fault isolation manual for further fault analysis. The action blocks also contain any required reference to locator data, schematic or wiring diagrams, or job guide function in parentheses (Fig. 24).

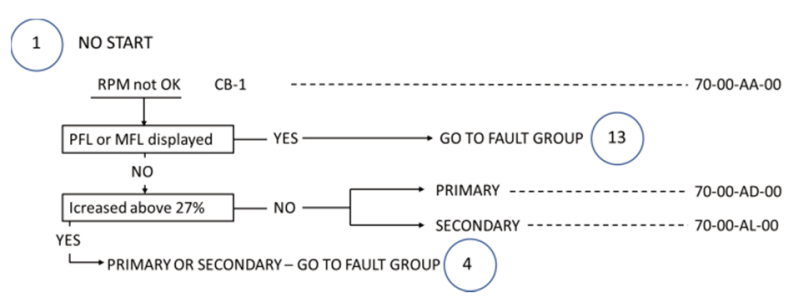

Fig. 24. Fault Isolation Flow Chart [12]

The next step of the fault troubleshooting it to follow the procedures in the LOG BOOK REPORT (70-00-00) section of the aforementioned fault isolation manual (Fig. 25).

Information from the Log Book Reports leads to the fault tree. In this case: 70-00-AA (Fig. 25). Fault tree of our interest is described in the Fault Isolation Information (7000-00) (Fig. 26).

In our case scenario first step of the fault isolation procedure is to review even/fault data in accordance with the supplemental data described in Tables 9-1 and 9-5 (Fig. 26). Supplemental data from Table 9-1 provides the information about EMS data downloading procedures (Table 2).

\section{SECTION II \\ LOG BOOK REPORT (70-00-00) \\ PILOT DETECTABLE FAULTS}

\section{(1) AA No start; RPM not OK; Fault Tree 70- 00-AA}

AD No start; RPM not OK; no Pilot Fault List (PFL) or MFL displayed; did not increase above $27 \%$; primary. Fault Tree 70-00-AD

AL No start; RPM not OK; no PFL or MFL displayed; did not increase above 27\%; secondary. Fault Tree 7000-AL
AH Hot start (ground); FTIT high; no PFL or MFL displayed; did not exceed $1112^{\circ} \mathrm{C}$; exceeded $1098^{\circ} \mathrm{C}$ longer than 5 seconds; primary. Fault Tree 70-00-AH

AQ Hot start (ground); FTIT high; no PFL or MFL displayed; did not exceed $1112^{\circ} \mathrm{C}$; exceeded $1098^{\circ} \mathrm{C}$ longer than 5 seconds; secondary. Fault Tree 70-00-AQ

Fig. 25. Log book report (Fault code 70-00-AA) [12]

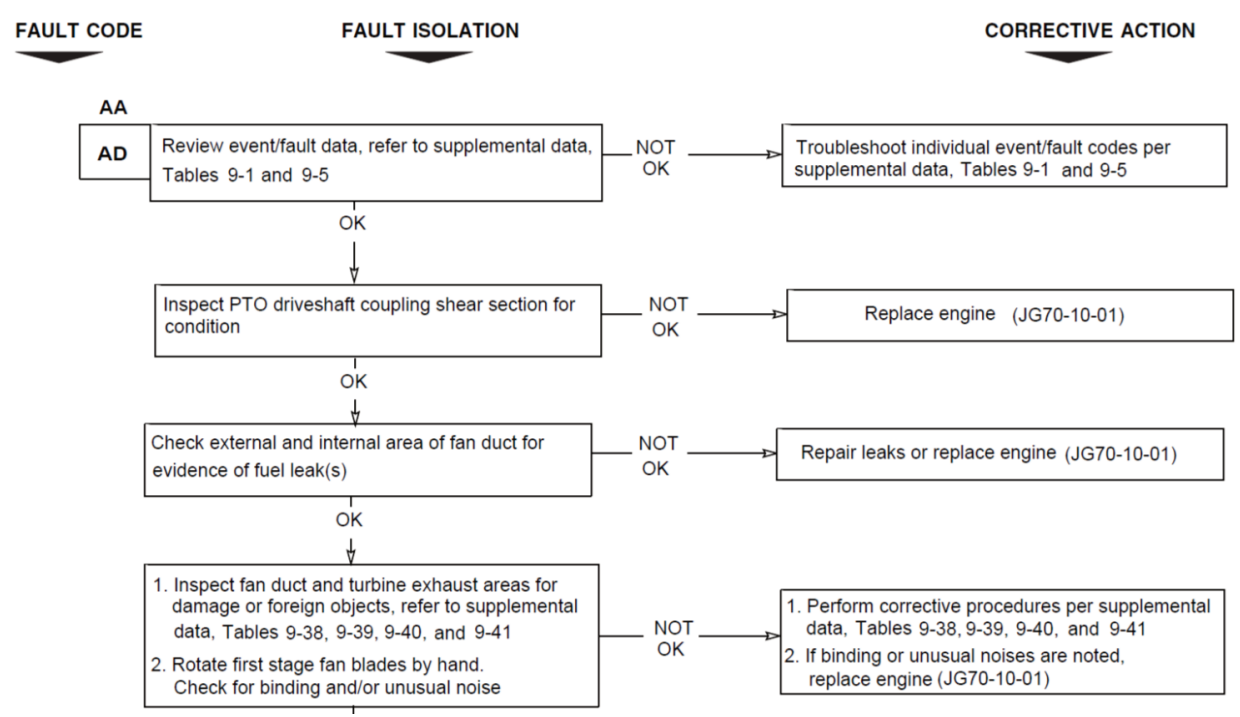

Fig. 26. Fault tree. Fault isolation information [12] 
Table 2. Fault Data Review procedure

\begin{tabular}{|l|c|c|}
\hline \multicolumn{1}{|c|}{ PROCEDURE } & $\begin{array}{c}\text { NORMAL } \\
\text { INDICATION }\end{array}$ & \multicolumn{1}{|c|}{$\begin{array}{c}\text { REMEDY FOR ABNORMAL } \\
\text { INDICATION }\end{array}$} \\
\hline $\begin{array}{l}\text { Aircraft safe for maintenance (JG10-30-01) } \\
\text { Power source: Battery }\end{array}$ & \\
$\begin{array}{l}\text { Support Equipment: Common Engine Transfer Set } \\
\text { 1. Open access door 3309 and 3316 }\end{array}$ & \\
$\begin{array}{l}\text { 2. Connect data download cable to receptacle J1 on CETS unit } \\
\text { 3. Connect data download cable to receptacle J146/1 } \\
\text { 4. Position laptop power switch to ON }\end{array}$ & \\
$\begin{array}{l}\text { 5. Select WinCEDS from menu shell program or double click on WinCEDS } \\
\text { icon }\end{array}$ & \\
$\begin{array}{l}\text { 6. With CET unit on main menu, select EDU COMMUNICATIONS } \\
\text { 7. Select EDU DOWNLOAD. Verify cable connection. Select OK }\end{array}$ & $\begin{array}{c}\text { No faults/events } \\
\text { displayed }\end{array}$ & $\begin{array}{l}\text { Troubleshoot existing events/faults per supplemental } \\
\text { data, Table 9-5. If communication error is displayed, } \\
\text { replace CETS and cables. If problem persists go to } \\
\text { fault code 77-00-ZF }\end{array}$ \\
\hline
\end{tabular}

If there are no engine fault codes downloaded from either EDU or DEEC then one should follow the Fault tree branch downwards from (Fig. 26). In case there are some fault codes downloaded one should follow the supplemental data in Table 9-5 (Table 3 and Table 4).

There are six basic types of events/faults. Each event/fault is identified with a four-digit code. A different series of numbers is used for each fault type; i.e., EDU events are 1000 to 1999 , DEEC faults 2000 to 2999, EDU faults 3000 to 3999, system faults 4000 to 4999, and EDU advisory faults 5000 to 5999, and 8000 series ITADS faults.

Intelligent trending and diagnostics system (ITADS) faults are displayed as four digit code numbers (8000 series) on the comprehensive engine trending and diagnostics system (CETADS) only after engine data is downloaded from the EDU and uploaded to the engine management computer running the CETADS software. ITADS only utilized takeoff performance data sets. It does not utilize ground performance data sets or test cell performance data [9].

Let us assume that the fault code downloaded was the 1120 (Table 5).

Corrective action should be followed in accordance with the chart "P" (Table 6). If the engine control mode was the PRIMARY MODE then one should go to fault code 70-00AD. In case it was SEC MODE - fault code 76-00-BG.

Following the Log Book Report (Fig. 27) one may find the right corrective action searching for the Fault tree 70-00-AD.

Part of the fault isolation procedure of the fault tree 7000-AD is shown in the Fig. 28.

Table 3. EDU event. EDU fault, DEEC fault, System fault and EDU advisory code reference

\begin{tabular}{|c|c|c|c|c|c|}
\hline MFL / PFL & FAULT CODES & EVENT/FAULT & \multicolumn{3}{|c|}{ CORRECTIVE ACTION } \\
\cline { 3 - 5 } CODES & & DESCRIPTION & CHART & TABLE E MIDAS FAULT CODE \\
\hline
\end{tabular}

Table 4. Supplemental data for EDU event, EDU fault, DEEC fault, system fault, cont.

\begin{tabular}{|c|c|c|c|c|c|}
\hline $\begin{array}{c}\text { MFL/PFL } \\
\text { CODES }\end{array}$ & FAULT & EODES & EVENT/FAULT & & \multicolumn{2}{c|}{ CORRECTIVE ACTION } \\
\cline { 3 - 5 } & & DESCRIPTION & CHART & TABLE & MIDAS FAULT CODE \\
\hline 023 & 4054 & RCVV Resolver Number 2 Position & & $76-00-Z Y$ \\
\hline 024 & 4050 & RCVV Resolver & & $76-00-Z S$ \\
\hline 025 & 1000 & Stagnation & A & \\
\hline
\end{tabular}

Table 5. Supplemental data for EDU event, EDU fault, DEEC fault, system fault, cont.

\begin{tabular}{|c|c|c|c|c|c|}
\hline \multirow{2}{*}{$\begin{array}{l}\text { MFL/PFL } \\
\text { CODES }\end{array}$} & \multirow{2}{*}{$\begin{array}{l}\text { FAULT } \\
\text { CODES }\end{array}$} & \multirow{2}{*}{$\begin{array}{l}\text { EVENT/FAULT } \\
\text { DESCRIPTION }\end{array}$} & \multicolumn{3}{|c|}{ CORRECTIVE ACTION } \\
\hline & & & CHART & TABLE & MIDAS FAULT CODE \\
\hline 036 & 1090 & N2 Overspeed & G & & \\
\hline 037 & 1120 & Engine No Start & $\mathrm{P}$ & & \\
\hline 038 & 1151 & Axial RCVV Flutter & $\mathrm{H}$ & & \\
\hline
\end{tabular}

Table 6. CHART P. Engine no start corrective procedures CHART P. ENGINE NO START

\section{NOTE}

- If fault was recorded during wet or dry motoring procedure, or engine depreservation, trouble shooting is not required.

- Following data may be obtained during engine data review to determine appropriate troubleshooting procedure: control mode (primary or secondary)

\begin{tabular}{|c|c|}
\hline PRIMARY & SECONDARY \\
\hline A & B \\
\hline \multicolumn{2}{|c|}{ CORRECTIVE ACTION } \\
\hline "A"- Go to fault code 70-00-AD & "B"- Go to fault code 76-00-BG \\
\hline
\end{tabular}


Let us assume one have reached to the point when we should check main fuel gear pump filter assembly IAW supplemental data from Table 9-32 (Table 7).

While inspecting fuel filter one finds it clogged by a foreign material. Then one should install filter IAW Job Guide JG73-00-09 (Table 8).

The next step of the troubleshooting procedure is to perform engine start and leak check IAW (JG70-00-01) as a follow-on maintenance of the MFGP Fuel Filter element, removal and installation procedure IAW T.O PL1F-16CJ-273JG-00-21 (Table 9).

This step ends fault isolation procedure. As a result of the case study research we may propose the Engine Discrepancy Removal Schematic Diagram (Fig. 29).

\section{NO START}

AA No start; RPM not OK; Fault Tree 7000-AA
AD No start; RPM not OK; no Pilot Fault List (PFL) or MFL displayed; did not increase above 27\%; primary. Fault Tree 70-00-AD

Fig. 27. Log Book Report (Fault code 70-00-AD)

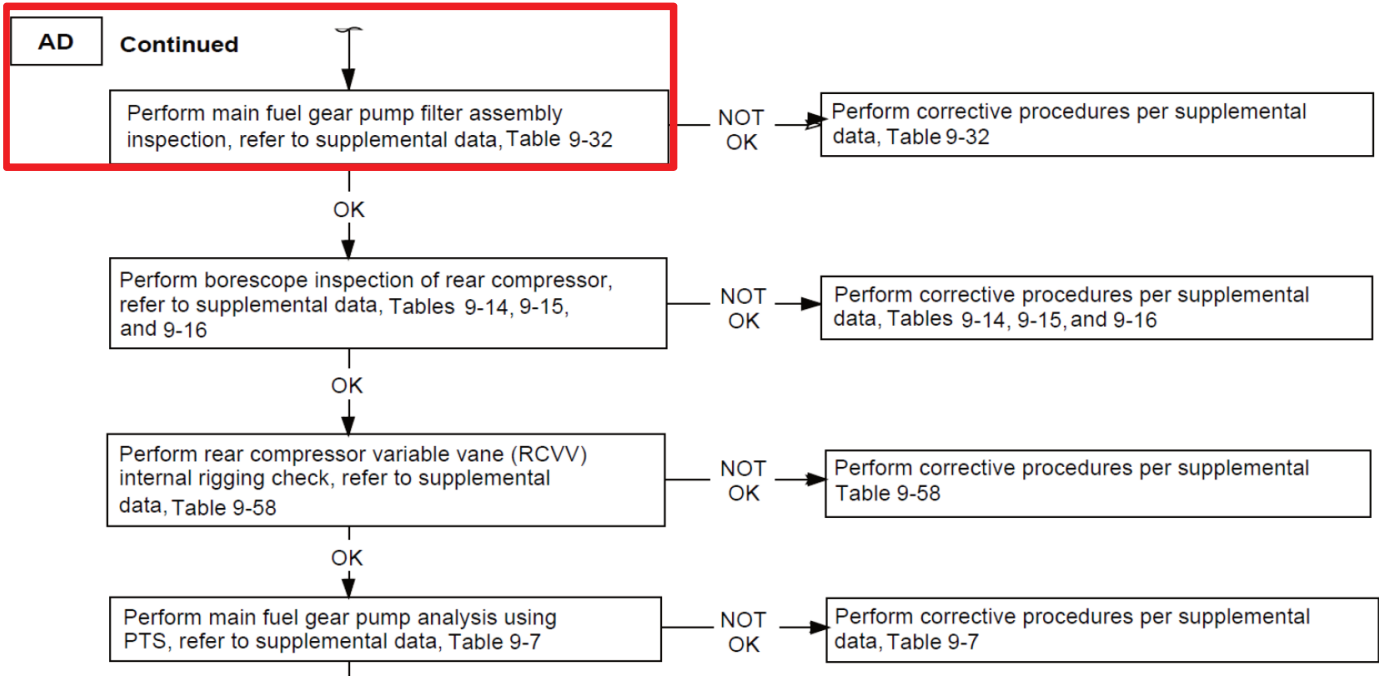

Fig. 28. Part of the Engine Fault Tree (Engine Fault 70-00-AD)

Table 7. Supplemental data. Main fuel gear pump filter assembly inspection procedure (part of Table 9-32)

\begin{tabular}{|c|c|c|c|}
\hline \multirow{2}{*}{\begin{tabular}{c} 
Instructions for main fuel gear pump filter assembly inspection are unique to gear / pump bypass valve configuration \\
1. $\quad \begin{array}{l}\text { Remove main fuel gear pump filter (JG73-00-09) } \\
2 . \quad \text { Visually inspect filter assembly (Figure 9-48) as follows: }\end{array}$ \\
\hline $\begin{array}{c}\text { INSPECTION } \\
\text { AREA }\end{array}$
\end{tabular}$\quad \begin{array}{c}\text { CONDITION } \\
\text { VICEABLE LIMITS }\end{array}$} \\
\hline Fuel filter cover & Cracks or distortion & None & CORRECTIVE ACTION \\
\cline { 2 - 4 } & $\begin{array}{c}\text { Stripped, crossed or worn } \\
\text { threads }\end{array}$ & None & Replace cover \\
\cline { 2 - 4 } & $\begin{array}{c}\text { Packing groove for wear and } \\
\text { foreign material build-up }\end{array}$ & None & Remove foreign material. If grooves are damaged, replace cover \\
\cline { 2 - 4 } & $\begin{array}{c}\text { Differential pressure indicator } \\
\text { housing operation }\end{array}$ & $\begin{array}{c}\text { If housing is damaged or operation is not smooth, replace cover. After } \\
\text { check, reset differential pressure indicator by inverting fuel filter cover } \\
\text { and pressing button. If indicator does not reset, replace differential } \\
\text { pressure indicator (JG73-00-25) }\end{array}$ \\
\hline
\end{tabular}

Table 8. Troubleshooting procedure for the clogged filter (part of Table 9-32), cont.

\begin{tabular}{|c|c|}
\hline PROCEDURE \\
\hline $3 . \quad$ Install main fuel pump filter (JG73-00-09) \\
\hline
\end{tabular}

Table 9. Part of the MFGP Fuel Filter element, removal and installation procedure

\begin{tabular}{|c|}
\hline TO PL1F-16CJ-2-73JG-00-21 \\
\hline FOLLOW-ON MAINTENANCE: \\
\hline$\bullet \quad$ (2) Perform engine start and leak check (JG70-00-01). \\
\hline
\end{tabular}




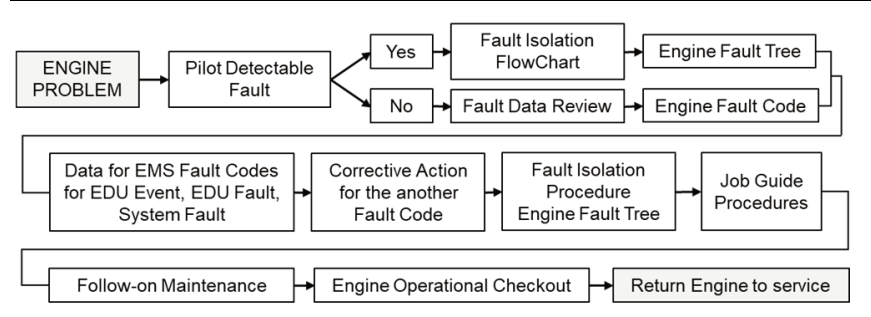

Fig. 29. Engine discrepancy removal schematic diagram. Own elaboration

\section{Summary}

Engine Monitoring System (EMS) is the key element in the engine prognostic and health monitoring. This is also the integral part of the engine performance trending. It allows to track engine performance parameters and their projections using historical data. In cooperation with Prognostic Health Monitor (PHM) and Engine Management And Tracking System (EMATS) it allows engine maintenance personnel for an easier troubleshooting and improvements implementation (right maintenance in right time), Time Accumulated Cycles TACs counting, engine parameters analysis, life time usage and the possibility of forecasting engine life remaining time. As a result, it is possible to manage engine components replacement, modules, and forecasting spare parts in advance.

As most of the complex systems it requires special preparation and experienced personnel. It supports engine tracking personnel in their work but it will never replace experienced and qualified personnel in engine diagnosis and prognostics.

It is very important to stress that while performing engine discrepancies removal sometimes corrective actions described in the fault isolation manual are just the most probable solution of the encountered problem. It does not guarantee that all engine discrepancies found during flight operations could be removed with the proposed corrective actions. In many cases one goes through the whole engine troubleshooting process, reaches the end of the engine fault tree and does not find the solution for the encountered engine problem.

\section{Nomenclature}

\begin{tabular}{|c|c|c|c|}
\hline AJ & Exhaust nozzle area & FTIT & Fan Turbine Inlet Temperature \\
\hline \multirow[t]{2}{*}{ AJRATIO } & Exhaust nozzle area ratio (Aj CENC feedback / & GSC & Ground Station Computer \\
\hline & calculated Aj for choked nozzle) & ITADS & Intelligent Trending And Diagnostic System \\
\hline CEDS & Comprehensive Engine Diagnostic Set & LODCNT & Light Off Detector Count \\
\hline CEMS & Comprehensive Engine Management System & MFC & Main Fuel Control \\
\hline CENC & Convergent Exhaust Nozzle Control & MNAC & Aircraft Mach Number \\
\hline \multirow{2}{*}{ CETADS } & Comprehensive Engine Trending And & MOP & Main Oil Pressure \\
\hline & Diagnostic System & N1 & Fan speed \\
\hline CETS & Common Engine Transfer System & $\mathrm{N} 1 \mathrm{C} 2$ & Corrected fan speed \\
\hline CIVV & Compressor Inlet Variable Vanes & $\mathrm{N} 2$ & Core speed \\
\hline DEEC & Digital Electronic Engine Control & $\mathrm{PB}$ & Burner pressure \\
\hline EDU & Engine Diagnostic Unit & PLA & Power Lever Angle \\
\hline EHM & Engine Health Management & PT4 & Combustion chamber discharge \\
\hline EMB & Engine Management Branch & TAC & Total Accumulated Cycles \\
\hline EMS & Engine Monitoring System & $\mathrm{Tt} 2$ & Fan Inlet Total Temperature \\
\hline EOT & Engine Operating Time & WFAC & Augmentor fuel flow, core \\
\hline EPR & Engine Pressure Ratio & WFAD & Augmentor fuel flow, duct \\
\hline FLT & Fault & WFMFC & Main fuel control fuel flow \\
\hline
\end{tabular}

\section{Bibliography}

[1] Lockheed Martin STM 16-329PL (Poland Block 52) F100PW-229 Power Plant.

[2] F100 Pratt\&Whitney F100 WUC, October 2018.

[3] F100-PW-229 Periodic Engineering Excellence Reviev.

[4] Lockheed Martin Aero Flight Safety, Operations and Maintenance, June 2018.

[5] International Engine Management Program, October 2018.

[6] Technical Manual T.O.00-20-1 Aerospace Equipment Maintenance Inspections, Documentation, Policies and procedures.

[7] F100 Pratt\&Whitney F100 WUC, October 2018.
[8] Technical Manual General System Organizational Maintenance Power Plant Model F100-PW-229 Technical Order PL1F-16CJ-2-70GS-00-21.

[9] Engine Management and Tracking System EMATS Maintenix

[10] F100-PW-229 Engine Interactive Electronic Technical Manuals.

[11] Technical Manual Maintenance Instructions Intermediate Level Introduction and General Information Aircraft Engine F100-PW-229 Technical Order 2J-F100-56-1.

[12] Technical Manual Fault Isolation Organizational Maintenance Power Plant Model F100-PW-229 Technical Order PL1F-16CJ-2-70FI-00-21.

Sławomir Szrama, DEng. - Squadron Commander at $31^{\text {st }}$ Air Force Base Poznań-Krzesiny.

e-mail: s.szrama@ron.mil.pl 